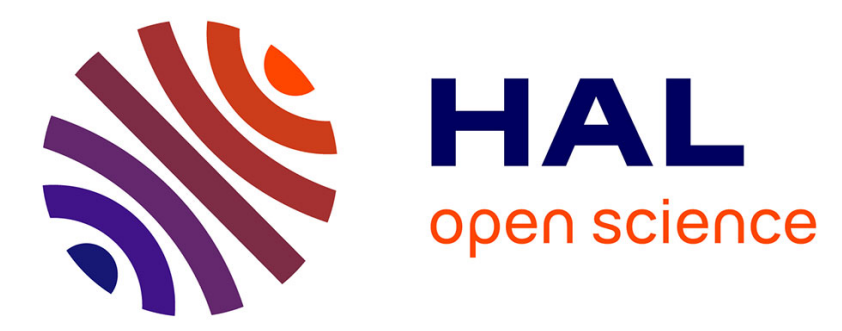

\title{
Flow behavior and microstructure in Ti-6Al-4V alloy with an ultrafine-grained alpha-single phase microstructure during low-temperature-high-strain-rate superplasticity
}

Hiroaki Matsumoto, Vincent Velay, Akihiko Chiba

\section{To cite this version:}

Hiroaki Matsumoto, Vincent Velay, Akihiko Chiba. Flow behavior and microstructure in Ti-6Al$4 \mathrm{~V}$ alloy with an ultrafine-grained alpha-single phase microstructure during low-temperature-highstrain-rate superplasticity. Materials \& Design, 2015, 66, p. 611-617. 10.1016/j.matdes.2014.05.045 . hal-01611092

\author{
HAL Id: hal-01611092 \\ https://hal.science/hal-01611092
}

Submitted on 26 Oct 2018

HAL is a multi-disciplinary open access archive for the deposit and dissemination of scientific research documents, whether they are published or not. The documents may come from teaching and research institutions in France or abroad, or from public or private research centers.
L'archive ouverte pluridisciplinaire HAL, est destinée au dépôt et à la diffusion de documents scientifiques de niveau recherche, publiés ou non, émanant des établissements d'enseignement et de recherche français ou étrangers, des laboratoires publics ou privés. 


\title{
Flow behavior and microstructure in Ti-6Al-4V alloy with an ultrafine-grained $\alpha$-single phase microstructure during low-temperature-high-strain-rate superplasticity
}

\author{
Hiroaki Matsumoto $^{\mathrm{a}, *}$, Vincent Velay $^{\mathrm{b}}$, Akihiko Chiba $^{\mathrm{c}}$ \\ a Department of Advanced Materials Science Faculty of Engineering, Kagawa University, 2217-20 Hayashi-cho, Takamatsu, Kagawa 761-0396, Japan \\ ${ }^{\mathrm{b}}$ Université de Toulouse, INSA, UPS, Mines Albi, ISAE, ICA (Institut Clément Ader), Campus Jarlard, 81013 Albi Cedex 09, France \\ ${ }^{\mathrm{c}}$ Institute for Materials Research, Tohoku University, 2-1-1 Katahira, Aoba-ku 980-8577, Japan
}

\begin{abstract}
A B S T R A C T
Grain refinement of Ti-6Al-4V alloy (hereafter designated as Ti-64 alloy) is well recognized as a method for revealing the superplasticity at lower temperature or higher strain rates. This work examines the superplastic flow behavior of the ultrafine-grained (UFG) Ti-64 alloy $\left(d_{\alpha}=0.4 \mu \mathrm{m}\right)$ consisting of single $\alpha$ phase in relation to microstructural evolution during deformation at $700^{\circ} \mathrm{C}$. Detailed microstructural evaluation reveals that the superplastic deformation mode of grain boundary sliding (tested at $700{ }^{\circ} \mathrm{C}$ $10^{-2} \mathrm{~s}^{-1}$ ) can be reasonably explained in relation to the Ball-Hutchison model at initial stage of deformation and the Gifkins Core-Mantle model at latter stage of deformation. During superplastic deformation, the $\beta$-precipitation occurs and contributes to accommodation mechanism of stress concentration at grain boundaries. This work also discusses the superplastic flow behavior in comparison with flow behaviors according to the Bird-Mukherjee-Dorn (BMD) generalized constitutive relation and the model which considers the effect of dynamic grain growth during deformation.
\end{abstract}

Keywords:

Titanium alloy

Superplasticity

Grain-boundary-sliding

Flow-behavior

\section{Introduction}

Ti-64 alloy is widely used in aerospace applications due to its high specific strength and high formability associated with superplasticity [1]. Grain refinement in Ti-64 alloy is well recognized as a method for revealing the superplastic behavior at lower temperatures or higher strain rates [2-4]. The Ti-64 alloys with an UFG microstructure produced by various kinds of processing routes (especially by severe-plastic-deformation routes) [2-4] exhibit the high strain rate sensitivity of the order of $0.35-0.65$ and high elongation to fracture $(\geqslant 400 \%)$ at temperatures $\left(700-800{ }^{\circ} \mathrm{C}\right)$ and strain rates $\left(\leqslant 10^{-3} \mathrm{~s}^{-1}\right)$. In superplastic deformation, an equiaxed grained microstructure is recognized to be desirable for enhancing superplastic property. Mallikarjun et al. have pointed out that an optimized microstructure for superplasticity in Ti alloys was a bimodal microstructure consisting of equiaxed primary $\alpha$ phase surrounded by lamellar $(\alpha+\beta)$ phase [5]. Recently, Boron addition with amount of $0.1 \mathrm{wt} . \%$ into Ti-64 alloy is reported to improve the superplastic response [6]. Roy and Suwas presented that the faster rate of dynamic globularization ensured a narrow distribution of

\footnotetext{
* Corresponding author. Tel.: +81 87864 2406; fax: +81 878642438

E-mail address: matsu_h@eng.kagawa-u.ac.jp (H. Matsumoto).
}

small, equiaxed primary $\alpha$ grains for the Ti-64 alloy with Boron addition ( $0.1 \mathrm{wt} . \%)$ which made up to an efficient $\alpha / \beta$ boundary sliding [7].

Quite recently, the present authors have presented that the UFG Ti-64 alloy (with an average grain size of $0.4 \mu \mathrm{m}$ ) consisting of almost single $\alpha(\mathrm{HCP})$ phase exhibited an excellent property of low-temperature and high-strain-rate superplasticity [8]. Herein, the $\beta$ precipitation during deformation is thought to contribute to the accommodation mechanism for stress-concentration at grain boundaries, thereby, leading to an excellent superplastic property. During large deformation associated with superplasticity, grain boundary sliding is recognized as dominant mode of deformation, however, many kinds of microstructural conversion process such as dynamic recovery, dynamic recrystallization, dynamic grain growth or dislocation slip should be complexly associated under deformation in specimens with microstructure having high dense dislocations. In stress-strain curves under tensile test, flow behaviors of work hardening and steady state manner are strongly related to the microstructural conversion as abovementioned.

In this work, the superplastic-flow-behavior in stress-strain curves of UFG Ti-64 alloy (with an average grain size of $0.4 \mu \mathrm{m}$ ) consisting of almost single $\alpha(\mathrm{HCP})$ phase would be examined and 
discussed it in relation to the microstructural conversions of grain boundary sliding, dynamic recrystallization and dynamic grain growth.

\section{Material and methods}

The Ti-64 alloy with a chemical composition (in wt.\%) of $6.50 \mathrm{Al}$, $4.24 \mathrm{~V}, 0.17 \mathrm{O}, 0.004 \mathrm{~N}$, and balance Ti was used. The Ti-64 alloy with UFG microstructure consisting of single $\alpha$ phase was produced as following deformation process.

The Ti-64 plate having an equiaxed $(\alpha+\beta)$ microstructure with thickness of $4 \mathrm{~mm}$ was solution treated at $1125^{\circ} \mathrm{C}$ for $3.6 \mathrm{ks}$ and quenching in ice water to obtain the single $\alpha^{\prime}$ martensite starting microstructure. This Ti-64 plate having an single $\alpha^{\prime}$ martensite microstructure with an initial thickness of $4 \mathrm{~mm}$ was hot-rolled at a strain rate (rolling speed) of approximately $7 \mathrm{~s}^{-1}$ to be thicknesses ranging from $1.4 \mathrm{~mm}$ to $1.0 \mathrm{~mm}$ (corresponding equivalent strains ranging from 1.2 to 1.6 ) by one pass. And hot rolling was conducted as soon as the samples were heated up to temperatures ranging from $750^{\circ} \mathrm{C}$ to $800^{\circ} \mathrm{C}$. This is for the frequent activation of discontinuous dynamic recrystallization (DDRX) during deformation in order to obtain the homogeneous UFG microstructure $[9,10]$.

Microstructures were identified by conducting electron backscatter diffraction (EBSD) analysis and Transmission electron microscopy (TEM) observation. In EBSD analysis, grain orientations were measured at step sizes of $0.12 \mu \mathrm{m}$ and $0.20 \mu \mathrm{m}$ using Philips XL 30 FEG SEM equipped with OIM of TexSEM Laboratories. Tensile test was conducted at temperatures of $650{ }^{\circ} \mathrm{C}, 700^{\circ} \mathrm{C}$ and $750{ }^{\circ} \mathrm{C}$ and at constant crosshead speeds to be initial strain rates ranging from $1.0 \times 10^{-4} \mathrm{~s}^{-1}$ to $1.0 \times 10^{-2} \mathrm{~s}^{-1}$ in Ar atmosphere.

\section{Results and discussion}

\subsection{Microstructural evolution during superplastic deformation}

\subsubsection{Initial microstructure before deformation}

Fig. 1 shows the microstructures ((a) EBSD-Grain boundary map (black line: high angle boundary $\left(\geqslant 15^{\circ}\right)$ and green line: low angle boundary $\left(2^{\circ} \leqslant \theta \leqslant 15^{\circ}\right)$ ) and (b) TEM bright field image) of the Ti64 alloy which was hot rolled of the $\alpha^{\prime}$ starting microstructure. Hereafter, this rolled Ti-64 plate would be called as the $\alpha^{\prime}$-UFG alloy. An UFG equiaxed microstructure having an average grain size of $0.4 \mu \mathrm{m}$ and relatively high fraction of high-angle-boundary

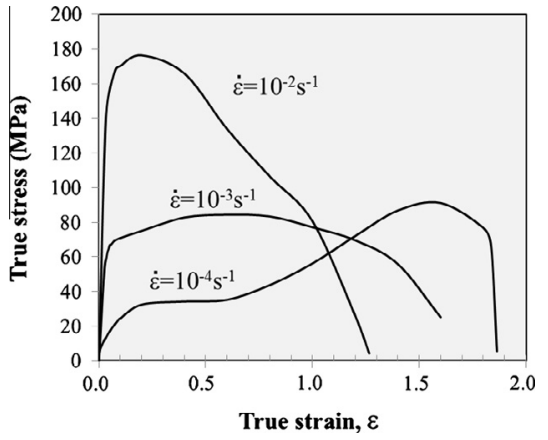

Fig. 2. True stress- true strain curves of the $\alpha^{\prime}$-UFG alloy tested at $700{ }^{\circ} \mathrm{C}-\left(10^{-2}\right.$ $10^{-3}$ and $\left.10^{-4}\right) \mathrm{s}^{-1}$.

(HAB) can be seen in the $\alpha^{\prime}$-UFG alloy. The elongated grains to rolling direction (RD) can be also confirmed (Fig. 1(a)). In TEM image (Fig. 1(b)), a significant amount of the fringe-diffraction contrast is seen in microstructure, indicating that highly dense dislocations are accumulated during hot-rolling process. Further, a selected area diffraction pattern taken with a diameter of $10 \mu \mathrm{m}$ (Fig. 1(b)) reveals the ring pattern, indicating that the microstructure locally consists of randomly oriented grains. Moreover, various kinds of analysis (EBSD analysis, TEM observation and the analysis of XRD pattern) reveal that the $\alpha^{\prime}$-UFG consists of an almost single $\alpha$ phase (HCP). With respect to the formation of this metastable single $\alpha$ microstructure, there is a possible reason that the $\beta$ precipitation is retarded due to the high-speed deformation of the $\alpha^{\prime}$ (HCP structure) starting microstructure. That is, it is supposed that there is no enough time for decomposition from $\alpha^{\prime}$ martensite to $\beta$ during the present rapid rolling process. However, it is still unclear why a metastable single $\alpha$ microstructure is formed under hot-deformation in the case of the $\alpha^{\prime}$ starting microstructure, thus, requiring more detailed investigation.

\subsubsection{Stress-strain curve during tensile deformation}

The true stress- true strain curves of the $\alpha^{\prime}$-UFG alloy tested at $700{ }^{\circ} \mathrm{C}-\left(10^{-2}, 10^{-3}\right.$ and $\left.10^{-4}\right) \mathrm{s}^{-1}$ are shown in Fig. 2. Large area of flow softening at $10^{-2} \mathrm{~s}^{-1}$ and steady state behavior of the flow curve at $10^{-3} \mathrm{~s}^{-1}$ can be seen. On the other hand, the flow behavior at $10^{-4} \mathrm{~s}^{-1}$ exhibits unique behavior, that is, the flow curve exhibits the steady state behavior to true strain of 0.6 followed by pronounced flow hardening to true strain of approximately
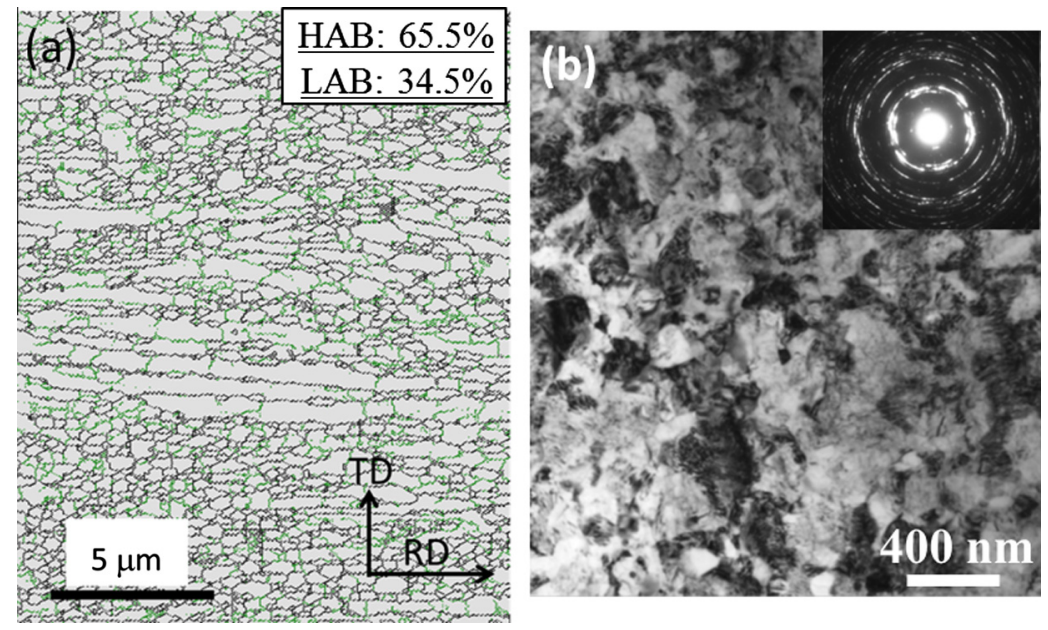

Fig. 1. (a) EBSD-grain boundary map (wherein the high- and low-angle boundaries are represented by black lines and green lines, respectively) and (b) TEM bright field image of the Ti-64 alloy which was hot rolled of the $\alpha^{\prime}$ martensite starting microstructure. (For interpretation of the references to color in this figure legend, the reader is referred to the web version of this article.) 

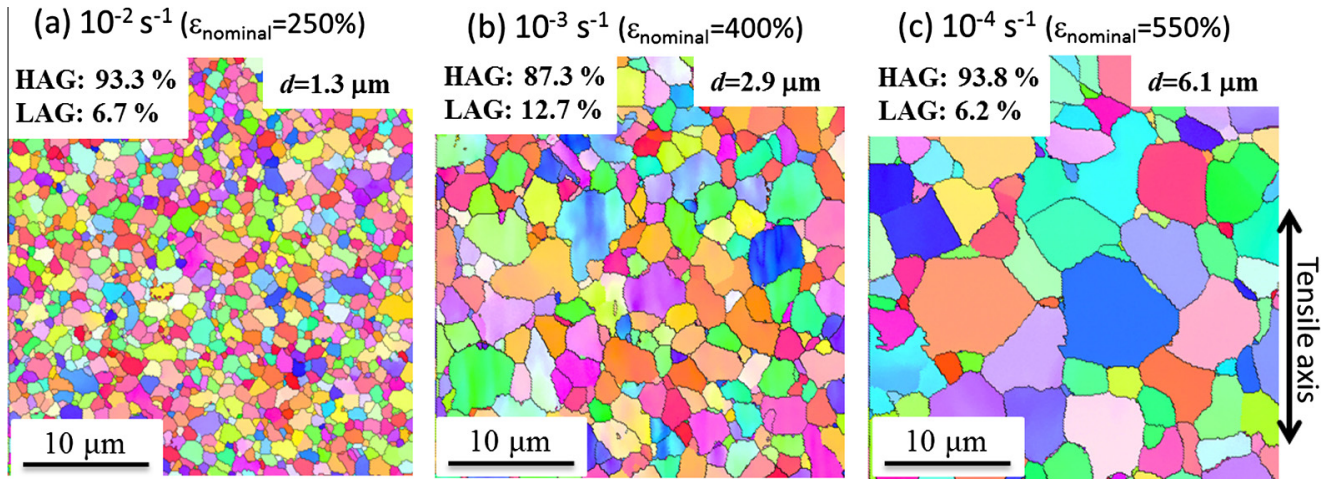

Fig. 3. EBSD-orientation images of the specimens after tensile fracture tested at (a) $700{ }^{\circ} \mathrm{C}-10^{-2} \mathrm{~s}^{-1}$, (b) $700{ }^{\circ} \mathrm{C}-10^{-3} \mathrm{~s}^{-1}$ and $(\mathrm{c}) 700{ }^{\circ} \mathrm{C}-10^{-4} \mathrm{~s}^{-1}$.

1.5. Flow behavior in steady state region indicates that grain boundary sliding or dynamic recovery process is dominant deformation mode. The pronounced flow hardening observed in testing at $10^{-4} \mathrm{~s}^{-1}$ implies that deformation mode dynamically changes during deformation. For all the above testing conditions, large elongations to failure more than $250 \%$ are observed in the $\alpha^{\prime}$-UFG alloy. A strain rate sensitivity $(m=\delta(\ln \sigma) / \delta(\ln \dot{\varepsilon}))$ of more than 0.3 is required for the superplastic deformation. The estimated $m$ values (at a true strain of 0.1 ) for the $\alpha^{\prime}$-UFG alloy are 0.31 at $650{ }^{\circ} \mathrm{C}, 0.38$ at $700{ }^{\circ} \mathrm{C}$, and 0.49 at $750{ }^{\circ} \mathrm{C}$, indicating that excellent elongation observed in the $\alpha^{\prime}$-UFG is derived from the occurrence of superplastic behavior.

Fig. 3 shows the EBSD-orientation images of tensile specimens after fracture tested at (a) $700{ }^{\circ} \mathrm{C}-10^{-2} \mathrm{~s}^{-1}$, (b) $700{ }^{\circ} \mathrm{C}-10^{-3} \mathrm{~s}^{-1}$ and (c) $700{ }^{\circ} \mathrm{C}-10^{-2} \mathrm{~s}^{-1}$. It can be seen a homogeneous equiaxed microstructure with random crystallographic orientations. And it can be observed that no cavities are formed even after large deformation. As compared with the initial microstructure of Fig. 1, the fraction of high angle boundary is noted to increase after tensile deformation. This result clearly indicates the occurrence of grain boundary sliding as the dominant deformation mode even at low temperature of $700^{\circ} \mathrm{C}$. Furthermore, remarkable grain-coarsening is observed in tensile specimen tested at $10^{-4} \mathrm{~s}^{-1}$ (Fig. 3(c)), indicating that the flow hardening during deformation (as shown in Fig. 2) is due to the occurrence of dynamic grain growth during deformation. The correlation of the flow hardening and dynamic grain growth during deformation would be discussed in later section.

\subsubsection{Deformation microstructure}

Quite recently, the present author has pointed out that dynamic $\beta$-precipitation at grain boundaries during deformation of the $\alpha^{\prime}$-UFG alloy played an important role as an accommodation mechanism, resulting in enhancement of superplastic behavior [8]. In order to identify the deformation mechanism more in detail, Fig. 4(a) and (b) show the TEM micrographs of deformed microstructures tested at $700{ }^{\circ} \mathrm{C}-10^{-2} \mathrm{~s}^{-1}$ and at true strains of (a) 0.41 (corresponding to nominal strain of 50\%) and (b) 0.69 (corresponding to nominal strain of $100 \%$ ). Fig. 4(c) is a selected area diffraction pattern taken with a diameter of $10 \mu \mathrm{m}$ of a tensile specimen tested at $700{ }^{\circ} \mathrm{C}-10^{-2} \mathrm{~s}^{-1}$ and at a true strain of 0.69 , reveals the ring pattern indicating that the microstructure consists of randomly oriented grains. Moreover, the reflections of $\beta$ phase are also confirmed in Fig. 4(c), indicating the occurrence of $\beta$-precipitation from metastable $\alpha$ starting microstructure. In order to confirm the $\beta$-precipitation in larger area, Fig. 4(d)-(f) represent the evolution of $\beta$-precipitation shown by EBSD-phase map (red ${ }^{1}$ phase: $\alpha$ phase

\footnotetext{
${ }^{1}$ For interpretation of color in Fig. 4, the reader is referred to the web version of this article.
}

and green phase: $\beta$ phase) during deformation at $700{ }^{\circ} \mathrm{C}-10^{-2} \mathrm{~s}^{-1}$ and at true strains of (d) 0 , (e) 0.41 and (f) 0.69 . According to these observations by TEM and EBSD, it can be observed that refined microstructure is remained even after large deformation and fine $\beta$-precipitation occurs at triple junction of grain boundaries. At true strain of 0.41 , TEM image (Fig. 4(a)) reveals the heterogeneous microstructure that consists of grains having high dislocationdensity and grains with a little density of dislocations. While, there is a decrease in dislocation density, accompanied by formation of homogeneous-microstructure with increasing strain to 0.69 (as shown in Fig. 4(b)). As already mentioned in previous report [9], there is no strong dislocation-accumulation inside of the grains but high dislocation-accumulation especially at the interface of $\alpha / \beta$ after tensile fracture (corresponding to the true strain of 1.27). Furthermore, fraction of high angle boundary in the $\alpha^{\prime}$-UFG alloy increased after superplastic deformation [9].

Fig. 5 shows the distributions of density of geometrically necessary dislocations (GNDs) after tensile deformation at $700{ }^{\circ} \mathrm{C}$ $10^{-2} \mathrm{~s}^{-1}$ and at true strains of (a) 0.41 and (b) 0.69 . A nonuniform plastic deformation is accompanied by the development of GNDs [11], which preserve the compatibility of the crystallographic lattice. GNDs are distinguished from the so-called statistically stored dislocations (SSDs), which are responsible of the plastic flow carried by crystallographic slips along distinct slip planes. The distributions of GNDs in Fig. 5 are calculated by the following simple method from the EBSD-kernel average misorientation (KAM) data [12], which follows the method reported by Kubin and Mortensen [13]. According to Calcagnotto et al., the KAM misorientation angle assumes a series of cylinder-torsion twist subgrain boundaries, each containing two perpendicular arrays of screw dislocations [12]:

$\rho_{\text {gnd }}=\frac{2 \Delta \theta}{\mu b}$,

where $\mu$ is the unit length $(=0.20 \mu \mathrm{m}$ in this work $)$ and $b$ is magnitude of the Burgers vector $\left(=2.95 \times 10^{-10} \mathrm{~m}\right)$. As a first-order approach, the KAM, which is retrieved directly from the EBSD data, was chosen as a measure of local misorientations. The KAM quantifies the average misorientation around a measurement point with respect to a defined set of nearest or nearest plus second-nearest neighbor points. Values above a predefined threshold (here, it is $2^{\circ}$ ) are excluded from the calculation, because these points are assumed to belong to adjacent grains or subgrains.

As similar to the TEM result (Fig. 4(a) and (b)), there is heterogeneous microstructure that consists of two types of grains with and without high amounts of dislocation-density in tensile specimen at a true strain of 0.41 (as shown in Fig. 5(a)). In contrast, there are no strong accumulation of dislocations and homogeneous microstructure in tensile specimen at a true strain of 0.69 . This 
(a) $\varepsilon=0.41\left(\varepsilon_{\text {nominal }}=50 \%\right)$

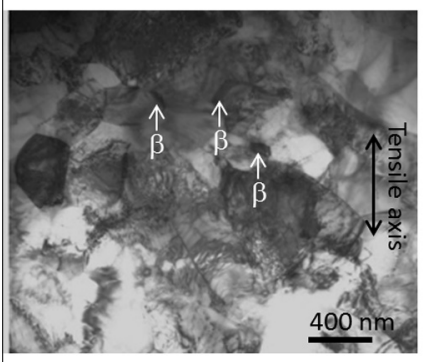

(b) $\varepsilon=0.69\left(\varepsilon_{\text {nominal }}=100 \%\right)$
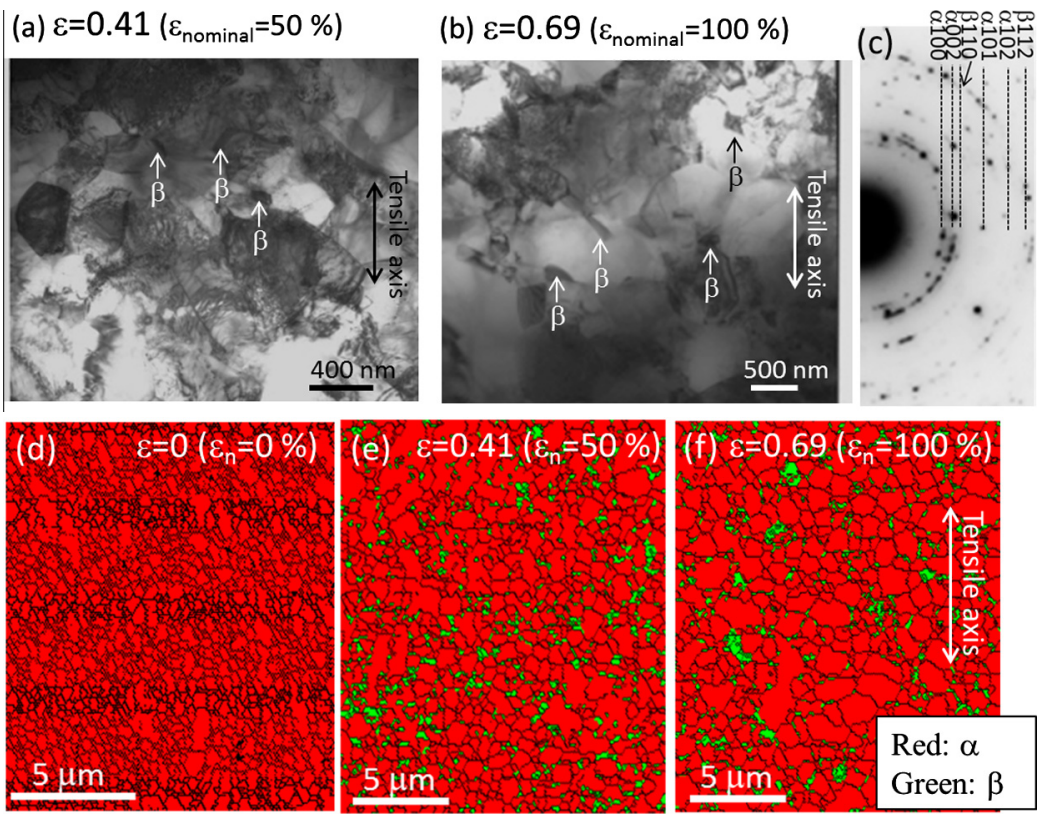

Fig. 4. Deformed microstructures of the $\alpha^{\prime}$-UFG alloy tested at $700{ }^{\circ} \mathrm{C}-10^{-2} \mathrm{~s}^{-1}$. (a and b) Bright field TEM images and (c) selected area diffraction pattern of tensile specimens at true strains of (a) 0.41 and (b and c) 0.69. EBSD-phase maps of tensile specimens at true strains of (d) 0 , (e) 0.41 and (f) 0.69 .
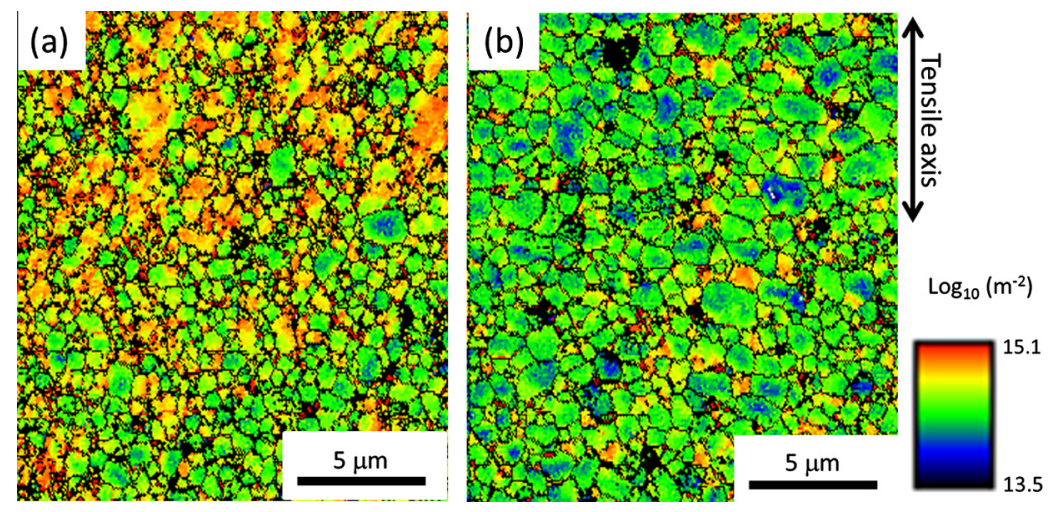

Fig. 5. The distributions of density of geometrically necessary dislocations (GNDs) of the $\alpha^{\prime}$-UFG alloy after tensile deformation at $700{ }^{\circ} \mathrm{C}-10^{-2} \mathrm{~s}^{-1}$ and at true strains of (a) 0.41 and (b) 0.69

result implies that active deformation mode under superplastic deformation is different depending on the amount of true strain.

When grain boundary sliding is obstructed by an unfavorably orientated grain, the resultant stress concentration may be relaxed by dislocation motion in the blocking grain. There are two typical models for activating the boundary sliding: the Gifkins CoreMantle model [14] and Ball-Hutchison model [15]. In this Gifkins Core-Mantle model, sliding is considered to take place by the motion of grain boundary dislocations which pile up at triple point. While, in the Ball-Hutchison model it is proposed that groups of grains slide as a unit. The resulting stress concentration is relaxed by the dissociation of the leading dislocation into dislocations capable of moving in the other boundaries which make up the triple point, and/or into lattice dislocations which accommodate sliding. The concept of the Ball-Hutchison model seems to be relatively close to the model of cooperative grain boundary sliding proposed by Kaibyshev et al. [16].

Previous reports $[17,18]$ have mentioned that superplasticdeformation-mechanism of Ti-6Al-4V alloy with an average grain size more than $3 \mu \mathrm{m}$ could be summarized in relation to the Gifkins Core-Mantle model [14]. In fact, the Gifkins Core-Mantle model is supposed to be dominant mode at latter stage of deformation (at $700{ }^{\circ} \mathrm{C}-10^{-2} \mathrm{~s}^{-1}$ and at a true strain of 0.69 ) of the $\alpha^{\prime}$-UFG alloy due to the characteristic of heterogeneous GNDs distribution that GNDs are strongly accumulated or accommodated especially at grain boundaries (as shown in Fig. 5(b)). This is in good agreement with the deformation mechanism of Ti-64 alloy $(d=3 \mu \mathrm{m})$ [18]. Whereas, deformed microstructure at a true strain of 0.41 (Fig. 5(a)) exhibits the heterogeneous microstructure composing of grains with and without accumulation of GNDs. This characteristic implies that deformation mode at initial and intermediate stages of deformation is supposed to strongly relate to the BallHutchison model or the cooperative grain boundary sliding model proposed by Kaibyshev et al. rather than the Gifkins Core-Mantle model. In addition to these models, the continuous dynamic recrystallization process should be occurred especially in deformed (elongated) grains in starting microstructure (Fig. 1(a)) at initial stage of deformation due to that initial microstructure of the $\alpha^{\prime}$-UFG alloy already contains highly dense dislocations (as shown in Fig. 1(b)). Thus, the detailed microstructural analysis of the deformed $\alpha^{\prime}$-UFG alloy reveals that the deformation mechanism becomes to be different as a function of true strain and superplastic 
deformation mode of grain-boundary-sliding is also complicatedly evolved in relation to $\beta$-precipitation, the occurrence of continuous dynamic recrystallization process and grain-growth during deformation.

\subsection{Constitutive behavior of stress-strain curves}

Superplastic deformation behavior of alloys can be described as a non-Newtonian viscos flow. The simplest constitutive equation is the Norton-Hoff power law relationship as,

$\sigma=K \varepsilon^{n} \dot{\varepsilon}^{m}$,

where $K$ is a constant and $n$ and $m$ are the strain hardening parameter and strain-rate-sensitivity parameter, respectively. And the above Eq. (2) can be restated in an the Bird-Mukherjee-Dorn generalized constitutive relation (BMD model) [19] as,

$\dot{\varepsilon}=\left(\frac{A D G b}{k T}\right)\left(\frac{\sigma}{G}\right)^{1 / m}\left(\frac{b}{d}\right)^{p}$.

This is the constitutive equation commonly used to describe elevated temperature deformation, in which $G$ is shear modulus, $b$ is Burgers vector, $k$ is Boltzmann's constant, $T$ is absolute temperature (Kelvin), $d$ is grain size of $\alpha$ phase and $p$ is the grain size exponent of the strain rate, $A$ is a constant and $D$ is a diffusion parameter.

With respect to the effect of flow-hardening due to dynamic grain growth during deformation, the Eq. (3) can be simplified to the following normalized form Eq. (4) $[17,20]$ :

$\frac{\sigma}{\sigma_{0}}=\left(\frac{d_{\alpha}}{d_{\alpha 0}}\right)^{p / n}$

in which $\sigma_{0}$ and $d_{\alpha 0}$ are the initial flow stress and initial grain size of $\alpha$ phase, respectively.

Dynamic coarsening of a $\alpha$-grain $\left(d_{\alpha}\right)$ as a function of time $(t)$ is expressed as following relation $[21,22]$ :

$d_{\alpha}^{3}-d_{\alpha 0}^{3}=K_{d}\left(t-t_{0}\right)=\left(K_{d} / \dot{\varepsilon}\right)\left(\varepsilon-\varepsilon_{0}\right)$

in which the subscript of ' 0 ' indicates quantities at initial stage, and $K_{d}$ denotes the dynamic coarsening rate constant. Fig. 6 shows the plots of $d_{\alpha}^{3}-d_{\alpha 0}^{3}$ vs $t-t_{0}$ at $700{ }^{\circ} \mathrm{C}$-tensile-testing (in which $d_{\alpha 0}$ $\left(t=t_{0}\right)$ denotes the average size at the initial time $\left.t_{0}\right)$, and contains the table showing the $\alpha$-grain size at respective time. The grain sizes of $\alpha$ phase in the tensile samples were experimentally determined by EBSD analysis. There is a well linear correlation between $d_{\alpha}^{3}-d_{\alpha 0}^{3}$ and $t-t_{0}$, indicating that coarsening kinetics was controlled by diffusion of solutes thorough the $\alpha$ phase. Herein, the $K_{d}$ in the $\alpha^{\prime}$-UFG alloy during tensile deformation at $700{ }^{\circ} \mathrm{C}$ is calculated to be $15.03\left(\mu \mathrm{m}^{3} / \mathrm{h}\right)$. According to the $K_{d}$ in Ti-64 alloy with the $(\alpha+\beta)$ microstructure $(\sim 2 \mu \mathrm{m}$ equiaxed-alpha particles in a matrix of beta (with an average beta-grain-size of approximately

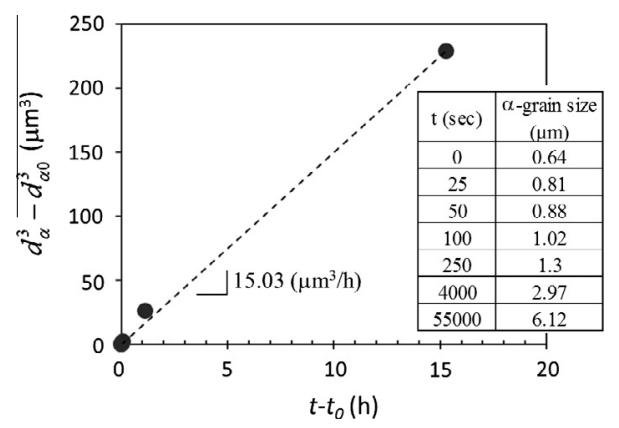

Fig. 6. Relationship of $d_{\alpha}^{3}-d_{\alpha 0}^{3}$ vs $t-t_{0}$ at $700{ }^{\circ} \mathrm{C}$-tensile-testing (in which $d_{\alpha 0}$ $\left(t=t_{0}\right)$ denotes the average size at the initial time $t_{0}$ ) with the table showing the $\alpha$ grain size at respective time.
$3 \mu \mathrm{m})$ ) [23], the $K_{d}$ values at respective tensile condition are 3.9 $\left(775^{\circ} \mathrm{C}-10^{-4} \mathrm{~s}^{-1}\right), \quad 8.8 \quad\left(775^{\circ} \mathrm{C}-10^{-3} \mathrm{~s}^{-1}\right)$ and $6.8 \quad\left(815^{\circ} \mathrm{C}-\right.$ $\left.10^{-4} \mathrm{~s}^{-1}\right)$, respectively. These values are quite smaller than the $K_{d}$ of the $\alpha^{\prime}$-UFG alloy (at $700{ }^{\circ} \mathrm{C}$-testing). As a characteristic of the $\alpha^{\prime}$-UFG alloy, an UFG microstructure $\left(d_{\alpha}=0.4 \mu \mathrm{m}\right)$ consisting of a single $\alpha$ phase is exhibited. Furthermore, there is high density of dislocation in the $\alpha^{\prime}$-UFG alloy. These characteristics of the $\alpha^{\prime}$-UFG alloy are supposed to accelerate the grain growth during deformation, thereby, resulting in high value of the $K_{d}$.

Flow behavior of the $\alpha^{\prime}$-UFG alloy tested at $700{ }^{\circ} \mathrm{C}$ would be discussed with comparing the above models in order to qualitatively clarify the deformation behavior. To evaluate the flow stress $(\sigma)$ according to BMD model (Eq. (3)), the term of $(1 / A D)^{m}$ is converted to the strain-dependent formula as following Eq. (6) and (7) on the basis of experimental result:

$$
\left(\frac{1}{A D}\right)^{m}=0.217 \varepsilon^{-0.103} \quad\left(\text { at } 700{ }^{\circ} \mathrm{C}-10^{-2} \mathrm{~s}^{-1}\right),
$$

$$
\begin{aligned}
\left(\frac{1}{A D}\right)^{m}= & 0.324 \varepsilon^{0.0792} \quad\left(\text { at } 700{ }^{\circ} \mathrm{C}-10^{-3} \mathrm{~s}^{-1}\right) \text { and } \\
& \times\left(\frac{1}{A D}\right)^{m}=0.408 \varepsilon^{0.201} \quad\left(\text { at } 700{ }^{\circ} \mathrm{C}-10^{-4} \mathrm{~s}^{-1}\right)
\end{aligned}
$$

in which $\varepsilon$ is true strain. The values of each parameter are summarized in Table 1.

Fig. 7 shows the stress-strain curves of experimental result, result of BMD model (3) and result of model considering dynamic grain growth (4) tested at $700{ }^{\circ} \mathrm{C}$ and at strain rates of (a) $10^{-2} \mathrm{~s}^{-1}$, (b) $10^{-3} \mathrm{~s}^{-1}$ and (c) $10^{-4} \mathrm{~s}^{-1}$. In the flow behavior of BMD model, the stress was calculated by using the true strain rate (calculated by following Eq. (8)):

$\dot{\varepsilon}=\frac{\dot{\varepsilon}_{0}}{\exp (\varepsilon)}$

$\dot{\varepsilon}_{0}$ : initial strain rate, $\varepsilon$ : true strain

At strain rate of $10^{-2} \mathrm{~s}^{-1}$ at which apparent grain growth does not occur during deformation, the flow behavior is shown in Fig. 7(a). Herein, the experimental flow curve (at true strains ranging from 0 to 0.4 ) is found to lie on between the flow curves of BMD model and grain growth model. With increasing strain from a true strain of approximately 0.4 , flow softening behavior associated with flow-localization is observed. In the above models, there is no consideration about the effect of flow localization, thereby, leading to large difference in flow behaviors among experimental and model's curves.

At strain rate of $10^{-3} \mathrm{~s}^{-1}$ (in Fig. 7(b)), flow stress of experimental curve is noted to be a little higher than that of BMD model, and pronounced flow-hardening and highest flow stress is seen in the result of grain growth model. On the other hand, at strain rate of $10^{-4} \mathrm{~s}^{-1}$ (in Fig. $7(\mathrm{c})$ ), flow stress in experimental curve exhibits steady state manner and is well consistent with the curve of the BMD model at the strains from 0 to 0.6 . With increasing strain from 0.6 , flow stress in experimental curve exhibits pronounced flow hardening and reaches to the similar stress-value with the result of grain growth model. In Fig. 7, grain sizes at specific strain after coarsening are also shown. According to Semiatin et al. [17,23],

Table 1

Material constants for the $\alpha^{\prime}$-UFG alloy tensile-tested at $700{ }^{\circ} \mathrm{C}$.

\begin{tabular}{ll}
\hline$d$ & $0.64 \mu \mathrm{m}\left(700{ }^{\circ} \mathrm{C}-0 \mathrm{~h}\right)$ \\
$m$ & 0.387 \\
$G$ & $25.2 \mathrm{GPa}$ \\
$k$ & $1.38 \times 10^{-23} \mathrm{~J} /{ }^{\circ} \mathrm{C}$ \\
$b$ & $0.295 \mathrm{~nm}$ \\
$p$ & 2 \\
\hline
\end{tabular}



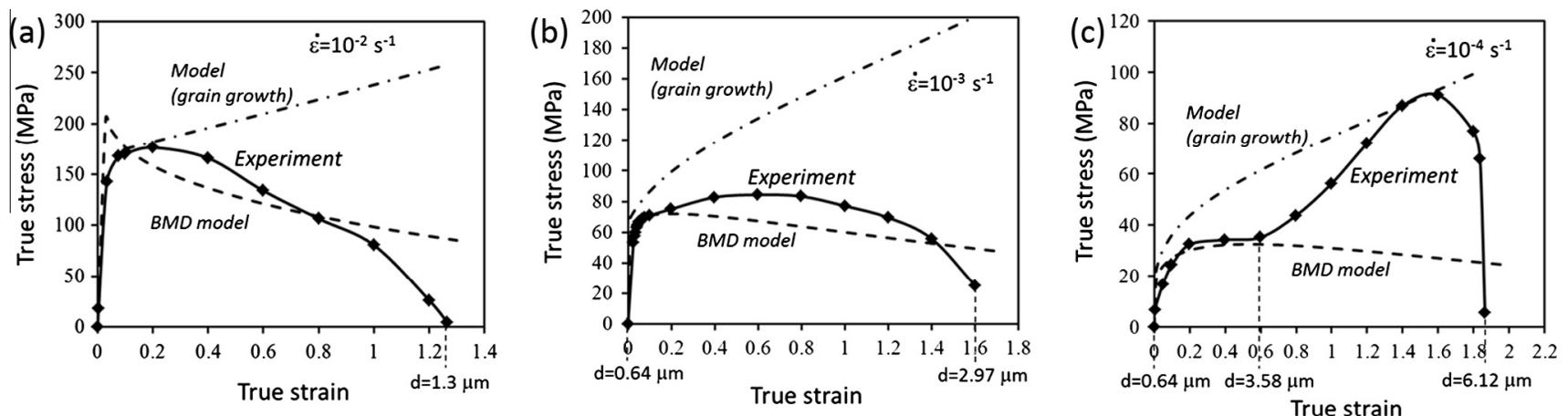

Fig. 7. Flow behaviors of experimental result, result of BMD model and result of model considering dynamic grain growth tested at $700{ }^{\circ} \mathrm{C}$ and strain rates of (a) $10^{-2} \mathrm{~s}^{-1}$, (b) $10^{-3} \mathrm{~s}^{-1}$ and (c) $10^{-4} \mathrm{~s}^{-1}$.

Ti-64 alloy having the equiaxed $\alpha$-particle $\left(d_{\alpha} \approx\right.$ approximately $2 \mu \mathrm{m}$ ) in a matrix of $\beta$ phase exhibits flow hardening during superplastic deformation at $775^{\circ} \mathrm{C}$ and $815^{\circ} \mathrm{C}$, and this flow behavior is well consistent with the result of grain growth model (4). During superplastic deformation of the $\alpha^{\prime}$-UFG alloy (as described in $3-1-3)$, the $\beta$-precipitation at grain boundaries and continuous dynamic recrystallization are simultaneously occurred especially at initial stage of deformation. In the experimental flow behavior at strain rate of $10^{-4} \mathrm{~s}^{-1}$, there is no apparent flow-hardening up to the strain of 0.6 (corresponding to the grain size of $3.58 \mu \mathrm{m}$ after dynamic growth) and its flow behavior (at initial stage of deformation) is observed to be well consistent with the result of BMD model. At strain rate of $10^{-4} \mathrm{~s}^{-1}$, dynamic restoration processes such as continuous dynamic recrystallization and dynamic $\beta$-precipitation are supposed to be already completed at quite initial stage of deformation. These microstructural evolutions are supposed to strongly relate to the suppression of flow hardening due to grain growth as shown in Fig. 7(b). In fact, Semiatin et al. pointed out that Ti-64 alloy ( $d_{\alpha} \approx$ approximately $3 \mu \mathrm{m}$ ) having the microstructure with the elongated-deformed-grains exhibited the dynamic spheroidization of remnant lamellae during superplastic deformation, thereby, resulting in flow softening $[17,23]$. The flow behaviors according to the models considering the grain growth (4) are reported to be well consistent with experimental superplastic-flow-behavior for the Ti-64 alloys (initial alpha particle size of approximately $2 \mu \mathrm{m}$ in a matrix of beta (with an average beta-grain-size of approximately $3 \mu \mathrm{m}$ ) before tensile test) with and without elongated deformation grains $[17,23]$. On the basis of this reported result and the experimental flow-behavior of the $\alpha^{\prime}$-UFG alloy (as shown in Fig. 7(c)) showing the pronounced hardening after grain-growth above the size of approximately $3.5 \mu \mathrm{m}$, it can be interestingly noted that there is little effect of grain size on apparent flow hardening in an UFG microstructure at grain size less than $3.5 \mu \mathrm{m}$ because the contribution of grain boundary sliding is much higher than that of flow hardening according to grain growth model (Eq. (4)). Meanwhile, the contribution of dislocation slip to deformation drastically increases when grain size exceeds the size of approximately $3.5 \mu \mathrm{m}$ at testing temperature of $700{ }^{\circ} \mathrm{C}$.

Let me summarize the constitutive behavior of stress-strain curve (tested at $700{ }^{\circ} \mathrm{C}$ ) of the $\alpha^{\prime}$-UFG alloy. The experimental flow curves did not lie on the predicted flow-curves which were based on the BMD model or the grain-growth model, although the experimental flow curves of $(\alpha+\beta)$ Ti-64 alloy having an equiaxed $\alpha$-particle $\left(d_{\alpha} \approx\right.$ approximately $2 \mu \mathrm{m}$ ) in a matrix of $\beta$ phase (with an average grain size of approximately $3 \mu \mathrm{m}$ ) are in good agreement with the predicted curves according to the BMD model and the grain-growth model. According to the comparison of flow behaviors (among experimental result and results of model) at a strain rate of $10^{-4} \mathrm{~s}^{-1}$ (in Fig. $7(\mathrm{c}$ )), it is found that there is no apparent effect of grain growth on flow behavior in grain sizes ranging from $0.64 \mu \mathrm{m}$ to approximately $3.5 \mu \mathrm{m}$. That is, in this grain-size region, the contribution of dislocation slip to active deformation mode is very small. On the basis of microstructural change during deformation of the $\alpha^{\prime}$-UFG alloy (as stated in Section 3.1.3), the complicated microstructural evolution associated with dynamic $\beta$-precipitation and the occurrence of continuous dynamic recrystallization during deformation of the $\alpha^{\prime}$-UFG is supposed to also relate to the unique behavior of experimental flow curve (in Fig. 7(c)).

\section{Conclusions}

This work examines the microstructural evolution of the $\alpha^{\prime}$-UFG alloy during low-temperature superplastic deformation at $700{ }^{\circ} \mathrm{C}$ (and at strain rates ranging from $10^{-4} \mathrm{~s}^{-1}$ to $10^{-2} \mathrm{~s}^{-1}$ ) and flow behavior of stress-strain curves in relation to the constitutive models (in Eqs. (3) and (4)).

Homogeneous equiaxed UFG microstructure is remained even after tensile fracture and fraction of high angle boundary increases during deformation, indicating that superplastic deformation in the $\alpha^{\prime}$-UFG alloy is mainly dominant by grain-boundary-sliding.

According to GND accumulation in deformed specimen tested at $700{ }^{\circ} \mathrm{C}-10^{-2} \mathrm{~s}^{-1}$, superplastic behavior at latter stage of deformation is explainable in relation to the Gifkins Core-Mantle model. On the other hand, the Ball-Hutchison model or the cooperative grain boundary sliding model proposed by Kaibyshev et al. should be dominant mode at initial and intermediate stages of deformation. Meanwhile, superplastic deformation mechanism (tested at $700{ }^{\circ} \mathrm{C}-10^{-2} \mathrm{~s}^{-1}$ ) of grain-boundary-sliding dynamically changes as a function of strain.

With respect to the flow behavior tested at $700{ }^{\circ} \mathrm{C}$ in comparison with the constitutive behaviors based on the BMD model and the model considering the grain growth, there is little accordance between the experimental flow curves and these predicted flowcurves at higher strain rate of $10^{-2} \mathrm{~s}^{-1}$, which is mainly due to that the models do not consider the effect of flow localization during deformation. While, experimental flow stress at $10^{-4} \mathrm{~s}^{-1}$ in steady state region (at strain ranging from 0 to 0.6 ) is well consistent with the result according to the BMD model, implying that there is little effect of dynamic grain growth on flow behavior in microstructure having an average grain size less than approximately $3.5 \mu \mathrm{m}$. That is, deformation mode of dislocation slip is supposed to frequently activate after dynamic grain growth $\left(d_{\alpha} \geqslant\right.$ approximately $\left.3.5 \mu \mathrm{m}\right)$ in testing at lower strain rate $\left(10^{-4} \mathrm{~s}^{-1}\right)$.

\section{Acknowledgement}

This research was supported by a Grant-in-aid from the Japan Society for the Promotion of Science (JSPS, Number 25709068). 


\section{References}

[1] Boyer R, Welsch G, Collings EW. Materials properties handbook, titanium alloys. Materials Park, OH: ASM International; 1994. p. 483-636.

[2] Mishra RS, Stolyarov VV, Echer C, Valiev RZ, Mukherjee AK. Mechanical behavior and superplasticity of a severe plastic deformation processed nanocrystalline Ti-6Al-4V alloy. Mater Sci Eng 2001;A298:44-50.

[3] Ko YG Kim WG Lee CS, Shin DH. Microstructural influence on lowtemperature superplasticity of ultrafine-grained Ti-6Al-4V alloy. Mater Sci Eng 2005;A410-411:156-9.

[4] Sergueeva AV, Stolyarov VV, Valiev RZ, Mukherjee AK. Enhanced superplasticity in a Ti-6Al-4V alloy processed by severe plastic deformation. Scripta Mater 2000;43:819-24.

[5] Mallikarjun K, Suwas S, Bhargava S. Effect of prior $\beta$ processing on superplasticity of $(\alpha+\beta)$ thermo-mechanically treated Ti-632Si alloy. J Mater Process Technol 2003;134:35-44.

[6] Roy S, Suwas S. Deformation mechanisms during superplastic testing of Ti6Al-4V-0.1B alloy. Mater Sci Eng 2013;A574:205-17.

[7] Roy S, Suwas S. Enhanced superplasticity for $(\alpha+\beta)$-hot rolled Ti-6Al-4V-0.1B alloy by means of dynamic globularization. Mater Des 2014;58:52-64.

[8] Matsumoto H, Yoshida K, Lee SH, Ono Y, Chiba A. Ti-6Al-4V alloy with an ultrafine-grained microstructure exhibiting low-temperature-high-strain-rate superplasticity. Mater Lett 2013;98:209-12.

[9] Matsumoto H, Lee SH, Ono Y, Li Y, Chiba A. Formation of ultrafine-grained microstructure of Ti-6Al-4V alloy by hot deformation of $\alpha^{\prime}$ martensite starting microstructure. Adv Eng Mater 2011;13:470-4.

[10] Matsumoto $\mathrm{H}$, Bin L, Lee SH, Li Y, Ono Y, Chiba A. Frequent occurrence of discontinuous dynamic recrystallization in Ti-6Al-4V alloy with $\alpha^{\prime}$ starting microstructure. Metall Mater Trans A 2013;44:3245-60.

[11] Ashby MF. The deformation of plastically non-homogeneous materials. Philos Mag 1970;21:399-424.
[12] Calcagnotto M, Ponge D, Demir E, Raabe D. Orientation gradients and geometrically necessary dislocations in ultrafine grained dual-phase steels studied by 2D and 3D EBSD. Mater Sci Eng 2010;A527:2738-46.

[13] Kubin LP, Mortensen A. Geometrically necessary dislocations and straingradient plasticity: a few critical issues. Scripta Mater 2003;48:119-25.

[14] Gifkins RC. In: Paton NE, Hamilton CH, editors. Superplastic forming of structural alloys. Warrendale: TMS-AIME; 1982. p. 3-26.

[15] Ball A, Hutchison MM. Superplasticity in the aluminium-zinc eutectoid. Metal Sci 1969;3:1-7.

[16] Kaibyshev OA, Pshenichniuk AI, Astanin VV. Superplasticity resulting from cooperative grain boundary sliding. Acta Mater 1998;46:4911-6.

[17] Semiatin SL, Sargent GA. Constitutive modeling of low-temperature superplastic flow of ultrafine Ti-6Al-4V sheet material. Key Eng Mater 2010;433:235-40.

[18] Kim JS, Kim JH, Lee YT, Park CG, Lee CS. Microstructural analysis on boundary sliding and its accommodation mode during superplastic deformation of Ti6Al-4V alloy. Mater Sci Eng 1999;A263:272-80.

[19] Bird JE, Mukherjee AK, Dorn JE. In: Brandon DG, Rosen A, editors. Quantitative relation between microstructure and properties. Jerusalem, Israel: Israel Universities Press; 1969. p. 225.

[20] Park CH, Lee B, Semiatin SL, Lee CS. Low-temperature superplasticity and coarsening behavior of Ti-6Al-2Sn-4Zr-2Mo-0.1Si. Mater Sci Eng 2010;A527:5203-11.

[21] Martin JW, Doherty RD, Cantor B. Stability of microstructure in metallic system. Cambridge, United Kingdom: Cambridge University Press; 1997.

[22] Sargent GA, Zane AP, Fagin PN, Ghosh AK, Semiatin SL. Low-temperature coarsening and plastic flow behavior of an alpha/beta titanium billet material with an ultrafine microstructure. Metall Mater Trans 2008;39A:2949-64.

[23] Semiatin SL, Fagin PN, Betten JF, Zane AP, Ghosh AK, Sargent GA. Plastic flow and microstructure evolution during low-temperature superplasticity of ultrafine Ti-6Al-4V sheet material. Metall Mater Trans 2010;41A:499-512. 